\title{
Student-Parents and Higher Education: a cross-national comparison Rachel Brooks
}

\section{Published in Journal of Education Policy}

\section{Introduction}

During its time in office, the UK's Labour government gave a strong message that having caring responsibilities for a young child should not be seen as a barrier to engaging in education and training. Its widening participation strategy (DfES, 2003) included a specific commitment to increasing the number of mature students in higher education (HE) - students who are more likely than their younger peers to have caring responsibilities for dependent children. Furthermore, considerable resources were devoted to encouraging teenage mothers to return to education and training soon after the birth of their child (SEU, 1997).

Nevertheless, despite this policy focus, there have been relatively few studies of the experiences of 'student-parents' within higher education. Moreover, the work that has been conducted in this area has tended to focus on a single institution (see, for example, Alsop et al., 2008; Marandet and Wainwright, 2009) and thus been rather limited in its scope. While there is a much more substantial literature on mature students, generally (e.g. McGivney, 1999; Reay et al., 2002; Schuetze and Slowey, 2002; Tett, 2000), it cannot be assumed that all student-parents fall into this category and certainly not all mature students have parental responsibilities. 
The extant body of literature - though small - has, however, played an important role in highlighting some of the difficulties faced by student-parents in the UK. These include: the challenges of juggling the temporal demands of being both a student and a parent of a young child; the paucity of on-site childcare facilities; restrictive 'no child on campus' policies; late availability of timetables; inconvenient timing of lectures; and acute financial pressures (Alsop et al. 2008; Marandet and Wainwright, 2009; Osborne et al., 2004). Similar findings have emerged from the US (Lynch, 2008). Research has also highlighted the tension experienced by many women between their identity as a mother and their identity as a student; indeed, Alsop et al. (2008) note that 'the fact that women have been traditionally the carers in the family, and that students have been conceptualised as male and non-carers, influences...the ways in which they are perceived by others, and also the manner in which their own identity is reconstructed' (p.629). It is argued that such tensions result in complex identity practices, as women downplay their mother role in academia and their student role when they are outside the university (Lynch, 2008).

Implicit in much of this work is an assumption that many of the problems faced by studentparents are inextricably linked to the wider political and social context within which universities are operating. For example, Marandet and Wainwright (2009) argue that the influence of neo-liberalist individualisation within the UK has tended to erase the significance of structural inequalities, with the effect of making student-parents believe that any difficulties they face are a result primarily of personal failures. Moreover, they contend that the commodification of higher education has resulted in the marginalisation of nontraditional students (including student-parents) who often have more complex and expensive needs than their peers. Other scholars have argued that societal norms about gender roles can also have a significant impact on student-parents. Osborne et al. (2004) argue that these affect 
both men and women: in their study fathers were often reluctant to enrol on a full-time higher education course because they saw it as in tension with their role as breadwinner, while women faced gendered expectations that they would be the main care-giver, irrespective of the demands of their university courses. However, as work to date has tended to focus on single-institution studies within one country only (typically the UK and US), it has been difficult to explore the impact of the wider social and political context on higher education students with parental responsibilities. In an attempt to address this gap, this paper compares the support for and understanding of student-parents in two countries with contrasting welfare systems.

\section{Research methods}

In order to explore the impact of the wider political and social context on the support offered to and experiences of student-parents, research was conducted in two European countries with significantly different 'welfare regimes' (Esping-Anderson, 1990; Gaille and Paugam, 2000): the UK and Denmark. The UK is an example of a 'liberal' welfare regime in which emphasis is placed on market supply of many welfare services and state involvement is typically through the provision of means-tested benefits to those on the lowest incomes. In contrast, Denmark is a 'social democratic' welfare regime, in which services are commonly provided on a universal (rather than selective) basis, and high value is accorded to achieving social equality.

To address the limitations of one-site studies, noted above, the research draws on data from four different higher education institutions (HEIs). Within both the UK and Denmark, data were collected at two HEIs with contrasting histories, market positions and geographical 
locations. These are referred to as 'Newer University’ and 'Older University’ within each country, and some key characteristics of the four institutions are provided in Table $1^{\mathrm{i}}$.

Different types of HEI within the same country were chosen to help explore the extent to which organisational culture and norms affect the experiences of student-parents, above and beyond national policy. It should be noted, however, that 'Older' and 'Newer' universities should not be assumed to be representative of all 'old' and 'new' universities, respectively. There are important differences between different types of 'older' and 'newer' universities, particularly within the UK. Moreover, although there are hegemonic policy discourses within both the UK and Denmark, there is also contestation within each national context. This limits the extent to which the findings can be generalised across either one of the two countries.

[Insert Table 1 about here]

Within each HEI, three main methods of data collection were used. Firstly, to develop a detailed contextual understanding of each of the four research sites, the universities were asked to provide copies of any policies or other material that focused on student-parents specifically. In addition, policies and/or other institutional material on childcare provision and sources of financial support were sought. These were analysed to assess the extent to which student-parents were addressed directly within university policy, and the sources of support that were available to this group of students. Secondly, individual, face-to-face interviews were conducted with two or three members of staff in each institution with responsibility for student welfare (in most cases, but not all, the interviewees were student advisers). Topics covered in the interviews included: whether the institution made any special provision for students with dependent children (and, if so, the nature of this); the childcare provision on offer, if any; the financial support offered to students; and respondents’ 
perceptions about the experiences of this group of students. Thirdly, individual interviews with conducted with between 15 and 20 student-parents from each of the four institutions, and were informed by both the document analysis and the interviews with members of staff. In both Denmark and the UK, interviews were conducted in English (although the Danish interviews were conducted by a researcher who was also fluent in Danish and had Danish citizenship). All interviews were recorded, fully transcribed and thematically coded. Patterns across the data collected at each site were first explored; comparisons were then made between sites.

As this paper focuses primarily on the support provided for student-parents, it draws from the first two data sources: the institutional documents and the interviews with members of staff responsible for student welfare. In analysing the transcripts from the staff interviews and the institutional documentation, particular attention was paid to structural issues (such as financial support and the provision of childcare) and cultural and attitudinal influences. This focus is derived, in part, from the literature on gender and employment, which has argued that, to understand the extent to which work and family life can be combined, it is insufficient to concentrate on only policies: organisational cultures are also of central importance in determining whether employees feel entitled to make use of their rights and how policies are actually implemented on the ground (Crompton et al., 2007; das Dores Guerreiro and Pereira, 2007). More specifically, previous studies of student-parents have also highlighted the impact of both structures and attitudinal factors on the experiences of this group of students (Lynch, 2008; Wainwright and Marandet, 2010).

The analysis is underpinned by a social constructionist theoretical framework, which assumes that individuals and groups play an active part in constructing meaning within their social 
environments and that there is no single 'student identity' which holds across all contexts. Just as the academic literature has problematised constructions of the 'non-traditional student' (Burke and Jackson, 2007; Hockings et al., 2008), so it is important to recognise both the variation in the experiences of students with dependent children, and some of the assumptions associated with the term 'student-parent' which do not necessarily map well onto the experiences of this group of students. For example, I have argued elsewhere (Brooks, 2011) that constructions of student-parents are often highly gendered, highlighting the 'problems' mothers face in juggling study and childcare, and masking those experienced by fathers.

\section{National differences}

Despite significant differences between the ‘welfare regimes' alluded to above, Crompton et al. (2007) note certain commonalities across Europe. Indeed, they argue that 'the pressures of competitive capitalism and modern managerial techniques can have a negative impact on individuals with caring responsibilities, whatever the national institutional context' (p.11). Moreover, some scholars who have focussed on education, specifically, have suggested that, over recent decades, we have witnessed the 'globalisation' of policy in this area, the widespread dominance of neo-liberal values and a significant reduction in the capacity of nation-states to pursue their own agendas (Cantwell and Maldonado-Maldonado, 2009; Montsios, 2009). Nevertheless, this section argues that in relation to student-parents at least, clear differences are evident between the UK and Denmark. These are apparent in both the structural support available to this group of students and the attitudinal factors which affect how they are understood and treated within institutional cultures. 


\section{Structural differences}

The interviews with members of staff responsible for student welfare highlighted important disparities between the UK and Denmark in four main areas: financial support; childcare provision; parental leave; and the availability of flexible modes of study. Key differences are summarised in Table 2.

[Insert Table 2 about here]

As the recent press coverage on fee differentials between the UK and some of its European neighbours has highlighted (e.g. Lightfoot, 2010; Vedrickas, 2010), there are clear differences between the two countries in the way higher education, generally, is funded (see also Brooks and Waters, 2011; OECD, 2010). The UK is characterised by relatively high tuition fees and the provision of loans to cover living costs for the large majority of students (only those from the lowest income families are entitled to grants). In contrast, Denmark does not charge tuition fees for its courses, and provides a grant to all students, regardless of income. In relation to student-parents, specifically, additional support is provided in the UK through a number of means-tested schemes: the Childcare Grant, Parents’ Learning Allowance and the Access to Learning Fund. However, in all cases, this funding is available only to those on low incomes and/or in considerable hardship. One student adviser at Newer University was typical of the UK staff who were interviewed in commenting that 'I don't think the government offers very much at all really [to student-parents], other than, you know, ticking a box by saying they can apply to the Access to Learning Fund'. In Denmark, in contrast, students who become parents during their studies are entitled to maternity and paternity pay, in addition to their student grant. This can be used flexibly, as one of the student advisers at the Danish Newer University explained: 
Everyone in Denmark will have money from the government. They have right to 70 months, one month is a 'cut'. We say one cut pays one month. They can have 70 cuts and when they are parents, when a woman she is a parent she gets 12 cuts more and the father will have 6 cuts more. The cuts they have they can use in three ways. They can have one cut each month and stay home for a year and then come back and continue their education or they can have two cuts every month so they can have double pay for half a year and then they come back or they can have, if they don't want to stay home, they can have one normal cut and one parent's cut and stay in the study and finish in the normal time. (Staff member 1, Newer University, Denmark)

As this quotation implies, taking a period of maternity or paternity leave during a degree is not uncommon; indeed, it is facilitated by the payment of the additional grant. All students who become parents are entitled to this, regardless of the stage of their degree they have reached or their academic performance. In the UK, however, not only is there no additional funding to support a period of parental leave, but there is no automatic right to taking 'time out' for this purpose. Indeed, one of the student advisers at Newer University in the UK explained that 'You have to be in a fairly good academic position for them [members of academic staff] to approve it....the student may get a different experience depending on whom they see’ (Staff member 1, Newer University, UK).

The extent to which flexible programmes of study are available to student-parents is a further significant difference between the two countries. The importance of flexible study packages to this group of students has been highlighted by previous studies in this field (e.g. National Union of Students, 2009; Marandet and Wainwright, 2009). Nevertheless, it appears that UK 
universities have made little progress in this area. Staff from both Newer and Older universities in the UK spoke of the difficulty of accommodating periods when a studentparent might not be able to attend classes or submit work because of a breakdown in childcare arrangements or the illness of a dependent child, for example. A member of staff from Older University explained that 'One of the big issues student-parents have is that...if their child is ill, what do they do with them?....because obviously tutors can only allow them to miss so much' (Staff member 1). In contrast, staff at the Danish higher education institutions explained how there was a legal requirement upon them to offer flexible study packages to student-parents, to ensure that they are able to complete their degree in the specified period of time:

Interviewer: Are you able to timetable the students in different ways because of their responsibility for children?

Staff member: Absolutely. The law says we have to do that and we have to make a programme, the law says, so that they can finish the education in the same amount of time. Of course, if they want to spend six months at home then the education will take six months more but not seven months. We have to make the education in the same time. (Staff member 2, Newer University, Denmark)

Indeed, the Danish interviewees cited a number of cases in which they had put together elearning packages to enable students who had children with long-term illnesses to study at home and thus complete their courses on time. Such behaviour was further incentivised by the funding mechanisms used by the government: as universities receive payment for each student who successfully completes his or her course, there are considerable rewards for offering flexible modes of study. 
Finally, the interviews with staff suggested that differences in the childcare provision available to student-parents were also significant. In both countries there are variations by institution in the childcare provided on-site. In the UK, Older University provides a number of its own nurseries for use by its students, while no dedicated facilities are provided by Newer University. Similarly, in Denmark, there is a crèche for use by student-parents at Older University, but no equivalent provision at Newer University. Nevertheless, the wider national provision of childcare was thought to be important. A number of UK respondents believed that an absence of cheap, flexible childcare made it difficult for parents who wished to enroll on a degree course. In Denmark, in contrast, no interviewee thought that potential students had been deterred from taking up a place at their institution through lack of childcare. Indeed, one of the members of staff at Newer University remarked that 'in Denmark there are kindergartens close to where you live and it is not difficult....so when your maternity leave is over, or your paternity leave, you almost every time have a place for your child' (Staff member 2). This is hardly surprising given the high level of national investment in childcare, discussed further below.

\section{Cultural and attitudinal differences}

Similar differences, by nation, were also evident in the attitudes of university staff and students and in the broader organisational cultures, as described by the interviewees. Research on mature students in the UK has argued that dominant discourses within higher education have tended to construct the 'ideal learner' in very limited (and masculinist) terms - as 'male, white, middle class and able-bodied, an autonomous individual, unencumbered by domestic responsibility, poverty or self-doubt' (Leathwood and O’Connell, 2003, p.599). These constructions are often then internalised by those who are positioned as 'other' within 
the discourse (Read et al., 2003; Burke, 2006). Moreover, it is argued that the academic culture which often follows from this view of the 'ideal learner' frequently privileges traits commonly seen as 'masculine' such as boldness, individualism and competitiveness (Read et al., 2003) and helps to foster a social environment that is geared primarily towards younger students (Marandet and Wainwright, 2010). In many ways, this reflects the way in which 'ideal workers' have been constructed in many organisations - which has led Crompton et al. (2007) to claim 'The anachronistic assumptions that ideal workers do not have active family responsibilities, and that full-time and uninterrupted work is a measure of occupational or professional commitment underpins this devaluing and continued gendering of alternative working patterns’'(p.241).

There was strong evidence that such attitudes remain prevalent, amongst some staff at least, in both UK universities in the sample. One of the staff members at Older University reported how one student-parent, with whom she had come into contact, had been told by her academic tutor that 'pursuing medicine [the student's degree course] and having a family is not very compatible' (Staff member 1). In this institution there seemed to be clear differences in attitude between some academic members of staff and those providing advice to students. Indeed, the respondent explained how such attitudes are 'shocking for us to hear, because we feel that, you know, students, it doesn't matter how old you are, what your circumstances are, if you're ready and willing to study, you know, you should be supported as much as possible'. Similar sentiments were expressed by some of the interviewees from Newer University in the UK, with one claiming, 'I think often our lecturers can treat the whole cohort as if they are 18 years of age and straight from school' (Staff member 3). However, there were also indications that some of those providing advice to student-parents did sometimes, themselves, problematise them as a group, as this quotation illustrates: 
Staff member: And I think sometimes parents can see it as possibly as a way to get out of the house and to have their own life and be themselves again....

Interviewer: Are you suggesting that actually for some [student-parents] it might be better if they don't come to university?

Staff member: Yeah, definitely! We’ve seen a few in here and they are just completely unprepared for university. Either you know generally in their life they are not prepared for it, or academically they're just not capable of it...And then it’s like, it’s really difficult for the university to weed them out. (Staff member 3, Newer University, UK)

Here, the 'unpreparedness' for university life is viewed as the fault of the individual student alone. Preparing for the transition to higher education study is thus seen as exclusively their responsibility, not something to be shared with the receiving institution. In many ways, this resonates with Ledwith and Manfredi’s (2000) findings in their analysis of policies to promote gender equality within the HE sector. They contend that:

Problems of gender discrimination are rendered into 'problems' with women, leading to liberal-style proposals for equal opportunities policies and practices being put into place, voluntarily, to help women comply with existing institutional requirements rather than the academy examining how it might fit itself better to the complexities of women’s lives. (p.12)

Within Denmark, in contrast, interviews with staff provided evidence of rather different organisational cultures and assumptions about the lives and motivations of the student body. 
Firstly, there seemed to be greater recognition of potential diversity among students. For example, one student adviser at Older University described how, before embarking upon a group project, she encouraged all students to discuss explicitly the other commitments they had in their lives, so that they could be aware of the constraints their fellow group members were working under, and be sensitive to these when planning group meetings, setting group deadlines and allocating work. Secondly, there was no evidence of those with parental responsibilities being problematised in any way (as indicated in some of the quotations and extant literature from the UK, outlined above). On the contrary, in some situations they were held up as role models to other students, as one respondent from Newer University explained:

Three times during the first year of studying we have counselling in small groups from each class where we talk to the students about being a good student.....Actually, the students without children are learning a lot from listening to the others [i.e. the student-parents] talk about how to manage and how to plan. (Staff member 2, Newer University, Denmark)

Moreover, constructions of an 'ideal student' did not conform to those discussed in the UK literature. Indeed, student-parents were often believed to have more balanced, and thus healthier, attitudes to studying than many of their fellow students who did not have children: 'I think that is one of the main problems for other students [i.e. those without children] who are just studying and studying and want to be very ambitious and studying is the only thing in their life and they are not very good at making some free time’ (Staff member 1, Older University, Denmark). The staff who were interviewed in Denmark also suggested that, in general, students themselves appeared to view higher education as a supportive environment in which to have children. Respondents from both Older and Newer universities explained 
how many young adults were making a positive choice to have children while they were students:

In Denmark a lot of people are having their children during their study period because it is easier to get work when you finish if they already have their children.....When they go on to university a lot of them will decide to have their children in the two last years so they have got them before they have to work. (Staff member 1, Newer University, Denmark)

While this quotation raises interesting questions about the extent to which family-friendly policies have been implemented within Danish workplaces, it does suggest that culturally, as well as structurally, Danish universities are perceived as providing considerable support to students with parental responsibilities.

\section{Explaining national differences}

Clearly many of the structural differences in the support provided to student-parents between the UK and Denmark, discussed above, are related to, if not explained by, the different ways in which higher education is funded in the two nations. However, it seems likely that social policy in other areas has also influenced the way in which student-parents are constructed. There appears to be a stark contrast between the attitudes of some UK academics, reported above - hostile to women pursuing a degree while also having responsibilities for young children - and more family-friendly norms within Danish universities, in which studentparents are sometimes held up as 'ideal students'. Given the well-documented relationship between constructions of gender within national policy and behaviour at the local level (Almqvist, 2008; Braun et al., 2008; Crompton et al., 2007), it seems likely that policies to 
promote a 'dual worker' (instead of a 'male breadwinner') model in place in Denmark since the 1970s, may well help to explain the attitudinal and cultural support provided to studentparents with Danish universities. The 2006 European Social Survey revealed that a greater proportion of people in Denmark 'approved' of a woman with children under three having a full-time job than in any other European country (Saraceno, 2011). This cultural acceptance of women engaging in paid work when their children are young may help to explain why it is rarely seen as problematic if they return to study at this point in their lives. Indeed, as a respondent from Newer University remarked, 'It is very rare for women in Denmark to stay home and take care of their children. In fact, it is something we talk about [because it's so rare] - "Oh, she is staying home and taking care of her children!”' (Staff member 2, Newer University, Denmark). In contrast, within the UK, the shift from a male breadwinner model of gender relations to a more equal ‘adult worker’ model has been significantly slower (Lewis, 2001; Dobrowolsky and Jensen, 2005).

\section{Institutional variations}

A further difference between the UK and Denmark can be seen in the degree of institutional variation within each of the two countries. In Denmark, provision of specific kinds of support for student-parents did vary a little between Older and Newer universities. For example, as noted above, a dedicated nursery was provided for students at Older University - which offered very flexible childcare (including both whole days and one hour slots to cover single lectures). In contrast, no such facility was available at Newer University. There were also differences by subject area in the proportion of students who had parental responsibilities: as in the UK, postgraduate programmes and vocational fields of study were both thought by staff to recruit considerably more student-parents than undergraduate programmes and more 
academically-focused courses. However, on the whole, in terms of both structural support and the institutional culture, both Danish universities were very similar. This is perhaps unsurprising given that much of the support for student-parents, outlined above, was prescribed by the government and underpinned by state policy. As one of the respondents from Newer University commented, ‘Since the government does so much, we don’t have to see them [student-parents] as a special group' (Staff member 2). Furthermore, as most Danish PhD students are, in effect, paid the equivalent of a salary by their institution to fund their research, they are entitled to the same employment rights as members of staff - resulting in strong commonalities across universities.

In the UK, however, a markedly different picture emerged. The document analysis and staff interviews revealed much greater inter-institutional variation. This was notable with respect to both the structural support available to student-parents and the university culture. Older University, for example, provided significant practical support to its student-parent population. This included: several nurseries; holiday clubs for school-age children; dedicated bursaries; an advice service (to help find schools and childcare, and apply for benefits and other sources of funding); a guide to services within the university and the local area; and a regular newsletter. The university also funded a small number of dedicated childcare officers to run these services, who tried to anticipate the practical needs of this group of students. However, analysis of university websites would suggest that Older University is quite atypical within the UK in offering this degree of support. The level of structural support found at Newer University is perhaps more representative of the sector as a whole. It did not offer any dedicated childcare facilities or information packs, and no members of staff were employed with the specific remit of providing services to this group of students. Moreover, no financial support was offered, beyond that which was provided centrally, through the 
Access to Learning Fund. One respondent from Newer University commented, 'As with most institutions, we offer what we have to offer and not a lot else!' (Staff member 3). Another interviewee claimed that, when specific provision for student-parents had been considered in the past, it had been led, primarily, by commercial concerns - a crèche had been discussed, as a commercial venture, but not taken any further as it was thought unlikely to generate sufficient revenue, while holiday clubs had sometimes been run, but did not seem to meet the needs of those with children: 'They'd be like for two or three hours. It was hopeless!...I think it's more about generating income, making the most of facilities that aren't otherwise being used for students' (Staff member 2, Newer University). Unlike Older University, the interviewees gave no sense that they were actively attempting to anticipate the needs of student-parents. Indeed, one respondent stated that she believed the onus was very much on the student, to ask for what he or she needed, if it was not already being provided by the university: 'sometimes you have to ask for it to get it, and be more vocal about your need' (Staff member 2).

In part, the relatively high level of provision offered at Older University may be explained by its secure financial position (compared to other higher education institutions) and its prestigious reputation. As one of the members of staff from the university commented, 'I think [Older University] would want to see that it's supporting its students....because it has the prestige' (Staff member 2). This reflects findings from the US, which have highlighted disparities by institutional status in the support offered to student-parents. Lynch (2008), for example, has argued that the best provision can be found in the elite universities. In her study, the top graduate schools offered significantly more support than their lower status counterparts: 55 per cent of such schools offered paid maternity leave, for example, and 30 per cent offered childcare subsidies. These findings also resonate with Claire Callender's 
(2010) work on the provision of financial aid with UK higher education institutions. She has argued that, as a result of the high political profile of initiatives to 'widen participation', elite universities have more (social and political) need than their lower status counterparts to attract non-traditional students and, especially, those from poorer backgrounds. Thus, 'the most selective HEIs not only provided more needs-based aid than other institutions, but also their bursaries were the most valuable' (p.52). She goes on to suggest that HEIs with higher proportions of low income students, in contrast, 'used their institutional aid for a variety of purposes other than improving access - primarily to strengthen or defend their institutional position in the HE market' (p.53). Thus, it could be argued that within a higher education system that is market-led but also subject to considerable government pressure to 'widen participation', it is rational for higher status institutions that do not have a problem recruiting students with excellent academic credentials to provide more financial and other structural support as part of an attempt to attract non-traditional students. Similarly, Callender's thesis may explain why lower status institutions, such as Newer University, which have a relatively high proportion of non-traditional students may choose not to use their resources in this way.

When we turn to a comparison of the cultures of the two institutions, however, different patterns emerge which, in part, are not in line with the differences in structural support outlined above. In Newer University, although interviews with staff pointed to the dominance of a culture which was very much focused around assumptions about the 'traditional' student (i.e. young, single and without caring responsibilities), there was also evidence of significant variation between individuals and between different parts of the institution. For example, one respondent noted that, 
Some members of staff are fantastically supportive and sympathetic, and some think 'What are you doing here? You shouldn’t be here with your children. This isn’t a place for you because you can’t concentrate on your studies. You should be at home focusing on your children'. (Staff member 2, Newer University, UK)

In Older University, in contrast, it appeared that there was a much stronger and more dominant institutional culture which constructed the 'Older University student' in a very particular way, beyond that of the 'traditional' student. This is illustrated in the following quotations from one of the interviewees at the university:

[Older University] doesn’t work like other universities, you know. It’s really allconsuming...and that is the special [Older University] experience is being able to interact with all these different people on different subjects and, which is fantastic, but if you have a child....

So an undergraduate student, it would be quite a challenge if they were to become a parent because they are not allowed to work, socially it would be very much of a challenge because undergraduate students are supposed to live in college, have their meals in college, they are supposed to have a minimum number of meals [there] per term. (Staff member 1, Older University, UK)

It appeared that this perspective was shared by students. For example, one respondent described how, earlier in the year, she had had to rewrite the guide provided to all new students - originally written by a student - because of its emphasis on how difficult it was to be a student-parent at Older University. She explained: 'we had to change some of the 
information because there was a little bit of an angle of "it's very difficult to have children in [Older University]” and...we thought that if anybody happened to become pregnant, you kind of felt like, if you want to continue being a student in [Older University], you know, that...your best option would be to actually just get an abortion because you wouldn't be able to be a student-parent' (Staff member 1). In their analysis of government policies which focus on students with caring responsibilities, Alsop et al. (2008) contend that policy often focuses solely on the financial costs of care, not on wider aspects. They go on to argue that 'central to a more effective approach to facilitating the participation of student carers is a conceptualisation of care that recognises its pervasive and multidimensional nature and how it shapes students' experiences in financial, temporal, emotional and identity terms’ (p.633). The interviews with staff at Older University and analysis of relevant documents suggest that similar disparities are evident in this institution: the relatively high level of structural support for a UK HEI appears not to be matched by an equally supportive university culture. Indeed, the two seem to be in considerable tension.

While some studies of higher education institutions have concluded that there is a dominant culture across the sector - frequently described as middle class and masculine in orientation (Ledwith and Manfredi, 2000; Morley, 1999; Walkerdine et al., 2001), other research has pointed to more diversity. For example, Archer et al. (2003) have suggested that certain spaces within the sector, such as within post-92 universities and on part-time courses, have sometimes been constructed as working class ${ }^{\mathrm{ii}}$. Moreover, recent work by Diane Reay and colleagues (2010) has emphasised the importance of recognising different 'university habituses' and the ways in which they affect learner identities. On the basis of their work at four higher education institutions across England (Northern, Southern, Eastern and Midland), they argue that 'the rewards and recognition of being a university student are powerfully 
differentiated across the higher education field’ (p.120). They have also highlighted important differences in the extent to which identification as a 'university student' becomes an individual's main source of identity:

For the most part, students at Eastern do not develop an identity as a university student, and our case-study students’ primary source of identification is as local, working class and 'at college'. At Northern, students have a number of competing identities as university students, but also as local and working class. They are jostling work and family commitments with doing a degree, and often the first two overwhelm and take precedence over studying.... In contrast, at Southern and to a lesser degree Midland, being a university student becomes the individual's main source of identity. (p.115).

As the evidence presented above suggests, similar differences are reflected in the cultural variation between Older and Newer universities. In institutions such as Southern in Reay et al.’s research and Older University (in the UK) in the current study, it would seem that strong norms (and expectations) that students identify only with their course of study and university life militate against the inclusion of student-parents, for whom identity as a mother or father is likely to be of at least equal, if not greater, significance.

This disparity between UK universities, in both the level of structural support offered to student-parents and the institutional culture, can be seen as a further key difference from the position in Denmark, where much stronger similarities were apparent in the two universities. It seems likely that this difference can be explained by reference to the wider political environment. In keeping with the neo-liberal orientation of much UK social policy, less 
government support is provided for HE students than in Denmark (as shown in Table 1), and so universities have considerably more discretion about the level and nature of any additional support they provide. Furthermore, the UK higher education sector is much more marketdriven than its Danish counterpart; this system encourages universities to develop potentially very diverse policies and practices that are perceived to fit their particular market segment. It is also much more internally differentiated than the Danish HE sector, comprising a number of very high status institutions - three in the top ten, internationally - as well as many of much lower status (Times Higher Education, 2010). In contrast, none of Denmark’s universities are in the top 100, internationally (ibid.). Research has consistently shown how these differences in the UK are mirrored in the social characteristics of the students who attend them (Reay et al., 2005), which is, in itself, likely to exacerbate differences in institutional culture.

\section{Conclusion}

The preceding discussion has highlighted the considerable differences, by nation, in the support offered to student-parents within higher education and also in attitudes towards this group of students. Clear disparities between the UK and Denmark were evident in relation to financial support, childcare provision, parental leave and availability of flexible modes of study. Cultural and attitudinal differences also emerged. Danish institutions appeared to be more sensitive to potential diversity within the student body than their UK counterparts. Moreover, there was no evidence of Danish members of staff problematising student-parents in ways that were reported by some of the UK respondents. In large part, these patterns seem in line with the broader literature on the experiences of parents in the two countries. Scholars have highlighted considerable differences by 'welfare regime', including the high level of support for employed mothers and dual-earner families within social democratic regimes, 
such as Denmark, and the much lower levels of state support evident within neo-liberal regimes such as the UK (Crompton et al., 2007; Daly, 2011; Hearn and Pringle, 2006; Miller, 2011). Indeed, Denmark spends a greater proportion of its GDP on childcare (2.4 per cent) than any other country in the OECD (Bonoli and Reber, 2010). As a result, it is able to offer parents very affordable nursery places (Ranch, 2007) and has the highest proportion of children under three years of age in formal daycare - 62 per cent, compared with 26 per cent in the UK (Saraceno, 2011).

However, the research has also revealed important cross-national differences in the extent of inter-institutional variation. Despite differences in their history, geographical location and subject specialism, both Danish universities approached student-parents in very similar ways. In contrast, within the UK, significant differences were apparent between the two HEIs in the sample. Although a number of studies on working parents have emphasised differences within countries (Crompton et al., 2007; Le Feuvre and Lemarchant, 2007; Wall, 2007), they have contended that such differences are evident across all nations - even those with a strong social democratic or neo-liberal orientation. In contrast, with respect to student-parents specifically, this study suggests that variation is much more likely in the UK than Denmark. In developing this argument, the article has suggested that this is because of the differing political contexts within which Danish and English HEIs are operating. As a consequence of the market-driven, neo-liberal orientation of the UK system, universities have more discretion about the level and nature of any additional financial support they provide to students and are incentivised to develop policies and practices that fit their perceived 'market segment' rather than the more general student population. Moreover, the highly internally-differentiated nature of the UK higher education sector has been shown to militate against social diversity within the student body, which is likely to have a strong bearing on institutional culture. 
Within this context it is perhaps unsurprising that the relatively high levels of support for student-parents evident within the Danish institutions were not replicated in their UK counterparts.

\section{Acknowledgements}

I am very grateful to: the Nuffield Foundation for funding the research; Sarah Robinson and Victoria Young for carrying out the majority of the interviews; and the respondents who gave up their time to be interviewed. I would also like to thank the two anonymous referees, Carole Leathwood and the members of the Education, Identities and Social Inclusion research group at Brunel University, all of whom provided very useful comments on previous versions of this article.

\section{References}

Almqvist, A.-L. (2008) why most Swedish fathers and few French fathers use paid parental leave: an exploratory study of parents, Fathering, 6, 2, 192-200.

Alsop, R., Gonzalez-Arnal, S. and Kilkey, M. (2008) The widening participation agenda: the marginal place of care, Gender and Education, 20, 6, 623-37.

Archer, L., Hutchings, M. and Ross, A. (2003) Higher Education and Social Class London, Routledge. 
Bonoli, G. and Reber, F. (2010) The political economy of childcare in OECD countries: explaining cross-national variation in spending and coverage rates, European Journal of Political Research, 49, 97-118.

Braun, A., Vincent, C. and Ball, S. (2008) 'I’m so much more myself now, coming back to work' - working class mothers, paid work and childcare, Journal of Education Policy, 23, 5, 533-548.

Brooks, R. (2011) The construction of 'student-mothers' within higher education: a crossnational comparison. Paper presented to Gender and Education conference, Exeter University, $27^{\text {th }}$ April 2011.

Brooks, R. and Waters, J. (2011) Fees, funding and overseas study: mobile UK students and educational inequalities, Sociological Research Online 16, 2. Available online at: www.socresonline.org.uk/16/2/1.html (Accessed 12 July 2011).

Burke, P.-J. (2006) Men accessing education: gendered aspirations, British Educational Research Journal, 32, 5, 719-733.

Burke, P. J. and S. Jackson (2007) Reconceptualising Lifelong Learning: Feminist Interventions, London, Routledge.

Callender, C. (2010) Bursaries and institutional aid in higher education in England: do they safeguard and promote fair access? Oxford Review of Education, 36, 1, 45-62. 
Cantwell, B. and Maldonado-Maldonado, A. (2009) Four stories: confronting contemporary ideas about globalisation and internationalisation in higher education, Globalisation, Societies and Education, 7, 3, 289-306.

Crompton, R., Lewis, J. and Lyonette, C. (2007) Introduction: the unravelling of the 'male breadwinner’ model - and some of its consequences, in: Crompton, R., Lewis, J. and Lyonette, C. (eds) Women, Men, Work and Family in Europe, Basingstoke, Palgrave.

das Dores Guerreiro and Pereira (2007) Women’s occupational patterns and work-family arrangements; do national and organisational policies matters? , in: Crompton, R., Lewis, J. and Lyonette, C. (eds) Women, Men, Work and Family in Europe, Basingstoke, Palgrave.

Daly, M. (2011) What adult worker model? A critical look at recent social policy reform in Europe from a gender and family perspective, Social Politics, 18, 1, 1-23.

Department for Education and Skills (DfES) (2003) The Future of Higher Education London, The Stationery Office.

Dobrowolsky, A. and Jensen, J. (2005) 'Social investment perspectives and practices: a decade in British Politics’, in: Powell, M., Bauld, L., and Clarke, K. (eds) Social Policy Review 17 Bristol, The Policy Press.

Esping-Anderson, G. (1990) The Three Worlds of Welfare Capitalism Cambridge, Polity Press. 
Gallie, D. and Paugam, S. (2000) Welfare Regimes and the Experience of Unemployment in Europe Oxford, Oxford University Press.

Hearn, J. and Pringle, K. (2006) Men, masculinities and children: some European perspectives, Critical Social Policy, 26, 2, 365-389.

Hockings, C., Cooke, S., Bowl, M., Yamashita, H. and McGinty, S. (2008). Learning and teaching for diversity and difference in higher education: towards more inclusive learning environments (Teaching and Learning Research Briefing No. 41), TLRP, London.

Leathwood, C. and O’Connell (2003) 'It's a struggle': the construction of the 'new student' in higher education, Journal of Education Policy, 18, 6, 597-615.

Ledwith, S. and Manfredi, S. (2000) Balancing Gender in Higher Education. A Study of the Experience of Senior Women in a 'New' UK University, The European Journal of Women's Studies, 7, 7-33.

Le Feuvre and Lemarchant, C. (2007) Employment, the family and 'work-life balance' in France, in: Crompton, R., Lewis, J. and Lyonette, C. (eds) Women, Men, Work and Family in Europe, Basingstoke, Palgrave.

Lewis, J. (2001) The decline of the male breadwinner model: implications for work and care, Social Politics, 8, 2, 152-169. 
Lightfoot, L. (2010) A-level results 2010: Unable to get into uni? Go Dutch, students are urged, The Observer, 15 August. Available online at http://www.guardian.co.uk/education/2010/aug/15/clearing-foreign-universities-britishstudents (Accessed 31 March 2011.)

Lynch, K. (2008) Gender roles and the American academe: a case study of graduate student mothers, Gender and Education, 20, 6, 585-605.

Marandet, E. and Wainwright, E. (2009) Discourses of Integration and Exclusion: Equal Opportunities for University Students with Dependent Children?, Space and Polity, 13, 2, 109-125.

Marandet, E. and Wainwright, E. (2010) Invisible experiences: understanding the choices and needs of university students with dependent children, British Educational Research Journal, 36, 5, 787-805.

Miller, T. (2011) Making Sense of Fatherhood. Gender, Caring and Work Cambridge, Cambridge University Press.

McGivney, V. (1999) Returning Women: Their Training and Employment Choices and Needs Leicester: National Institute of Adult and Continuing Education.

Montsios, S. (2009) International organisations and transnational education policy, Compare, 39, 4, 469-81. 
Morley, L. (1999) Organising Feminisms: the micropolitics of the academy London, Macmillan.

National Union of Students (2009) Meet the Parents London, National Union of Students.

OECD (2010) Education at a Glance OECD, Paris.

Osborne, M., Marks, A. and Turner, E. (2004) Becoming a mature student: how adult applicants weight the advantages and disadvantages of higher education, Higher Education, 48, 291-315.

Ranch, D. (2007) Is there really a Scandinavian social service model? A comparison of childcare and elderlycare in six European countries, Acta Sociologica, 50, 3, 249-269.

Read, B., Archer, L. and Leathwood, C. (2003) Challenging Cultures? Student conceptions of 'belonging' and 'isolation’ at a post-1992 university, Studies in Higher Education, 28, 3, 262277.

Reay, D., Ball, S. and David, M. (2002) 'It's taking me a long time but I'll get there in the end': Mature students on access courses and higher education choices, British Educational Research Journal, 28, 1, 5-19.

Reay, D., David, M. and Ball, S. (2005) Degrees of Choice: social class, race and gender in higher education London, Trentham Books. 
Reay, D., Crozier, G. and Clayton, J. (2010) 'Fitting in’ or 'standing out': working class students in UK higher education, British Educational Research Journal, 36, 1, 107-124.

Saraceno, C. (2011) Childcare needs and childcare policies: a multidimensional issues, Current Sociology, 59, 1, 78-96.

Schuetze, H. and Slowey, M. (2002) Participation and exclusion: a comparative analysis of non-traditional students and lifelong learners in higher education, Higher Education, 44, 309327.

Social Exclusion Unit (SEU) (1999) Teenage Pregnancy (Command Paper 4342) London, The Stationery Office

Tett, L. (2000) 'I'm working class and proud of it': Gendered experiences of non-traditional participants in higher education, Gender and Education, 12, 2, 183-94.

Times Higher Education (2010) World University Rankings 2010 Available at: http://www.timeshighereducation.co.uk/world-university-rankings/2010-2011/top-200.html (Accessed 25 March 2011).

Vedrickas, G. (2010) Student fees: the answer may lie overseas, The Observer, 10 October. Available online at: http://www.guardian.co.uk/money/2010/oct/10/tuition-fees-studentsoverseas-universities (Accessed 31 March 2011.) 
Wainwright, E. and Marandet, E. (2010) Parents in higher education: impacts of university learning on the self and the family, Educational Review, 62, 4, 449-465.

Walkerdine, V., Lucey, H. and Melody, J. (2001) Growing Up Girl: psychosocial explorations of gender and class Basingstoke, Palgrave.

Wall, K. (2007) Main patterns in attitudes to the articulation between work and family life: a cross-national analysis, in: Crompton, R., Lewis, J. and Lyonette, C. (eds) Women, Men, Work and Family in Europe, Basingstoke, Palgrave. 
Table 1: Characteristics of the four higher education institutions involved in the research

\begin{tabular}{|c|c|c|}
\hline Pseudonym & Geographical location & Salient characteristics \\
\hline Newer University, UK & $\begin{array}{l}\text { Metropolitan area of } \\
\text { England }\end{array}$ & $\begin{array}{l}\text { A 'pre-92' university, but not a member of the Russell } \\
\text { Group }{ }^{\text {iii }} \text {. Does not rank highly in international league } \\
\text { tables. Relatively high proportion of non-traditional } \\
\text { students, many drawn from local area. Broad range of } \\
\text { subjects offered. }\end{array}$ \\
\hline Older University, UK & $\begin{array}{l}\text { Market town in } \\
\text { England }\end{array}$ & $\begin{array}{l}\text { High status institution; member of the Russell Group; } \\
\text { usually ranks highly in international league tables. Tends to } \\
\text { have relatively small numbers of non-traditional students. } \\
\text { Student body drawn from across the UK (and } \\
\text { internationally). Broad range of subjects offered. }\end{array}$ \\
\hline
\end{tabular}

\begin{tabular}{lll}
\hline Newer University, & Four sites, in non- & Gained university status relatively recently. Offers mainly \\
Denmark & metropolitan locations & applied and professionally-oriented undergraduate \\
& programmes such as nursing, education, social work and \\
& physiotherapy.
\end{tabular}

\begin{tabular}{ll}
\hline Older University, & Large town \\
Denmark & One of the largest universities in Denmark, founded in the \\
& 1970s. Offers wide range of undergraduate and \\
postgraduate programmes, many taught in English. Has & been known for innovative pedagogy, and a focus on \\
& project work rather than traditional lectures.
\end{tabular}


Table 2: Sources of support for student-parents in the UK and Denmark

\begin{tabular}{|c|c|c|}
\hline \multirow[t]{6}{*}{ Financial support } & $\begin{array}{l}\text { All students pay tuition fees (loan } \\
\text { available to cover this). }\end{array}$ & No tuition fees payable. \\
\hline & & Government grants for all undergraduate \\
\hline & $\begin{array}{l}\text { Maintenance grant payable to those on } \\
\text { low incomes; loans available for other }\end{array}$ & students. \\
\hline & students. & $\begin{array}{l}\text { Additional maternity and paternity grants } \\
\text { for student-parents (12 months and } 6\end{array}$ \\
\hline & $\begin{array}{l}\text { Some dedicated funding for student- } \\
\text { parents on low incomes or in financial }\end{array}$ & months, respectively). \\
\hline & $\begin{array}{l}\text { difficulty: Access to Learning Fund; } \\
\text { Childcare Grant; Parents’ Learning }\end{array}$ & $\begin{array}{l}\text { Salary for PhD students (equivalent to } \\
\text { junior lecturer). }\end{array}$ \\
\hline
\end{tabular}

Allowance.

\begin{tabular}{ll}
\hline Parental leave & $\begin{array}{l}\text { No automatic right to leave in all } \\
\text { institutions. Often at discretion of }\end{array}$ \\
academic staff. & by additional grant (see above).
\end{tabular}

\begin{tabular}{lll}
\hline $\begin{array}{l}\text { Flexible modes of } \\
\text { study }\end{array}$ & $\begin{array}{l}\text { At discretion of academic staff. Often not } \\
\text { offered. }\end{array}$ & $\begin{array}{l}\text { Higher education institutions required to } \\
\text { provide this by the state. Incentivised by }\end{array}$ \\
& payments to institutions for all students \\
& who complete their degree.
\end{tabular}

\begin{tabular}{lll}
\hline Childcare provision & Varies by institution. Some universities & University provision varies. \\
& provide nurseries and/or crèches; others & \\
do not. & Extensive provision, generally, by state, \\
& at low cost.
\end{tabular}

Reasonable high coverage of childcare, 
generally, but expensive.

\footnotetext{
${ }^{\mathrm{i}}$ It had been hoped to include HEIs with different numbers of student-parents. However, as preliminary research suggested that very few institutions in the UK or Denmark collected statistics on whether or not their students had dependent children, it was not possible to use this as a sampling criterion.

ii Previous work on mature students has tended to focus on those from working class backgrounds, and suggested that socio-economic status has a significant impact on both access to higher education and the experiences of students once at university. As this paper draws exclusively on the interviews with members of staff and analysis of policy documents, not the interviews with students, it is not possible to discuss here the impact of the students' social class. However, this is an important aspect of the ongoing data analysis, and is likely to be discussed in some detail in a subsequent paper from the project.

iii The Russell Group is a collaboration of 20 'research-led' UK universities. Parallels are often drawn between this grouping and the US 'Ivy League’.
} 